\title{
Changes of Foxo3a in PBMCs and its associations with stress hyperglycemia in acute obstructive suppurative cholangitis patients
}

\author{
Niu Bailin ${ }^{1, *}$, Chen Nann ${ }^{2,3, *}$, Li Peizhi², He Kun², Zhu Xiwen², Ren Guosheng ${ }^{4}$, Gong \\ Jianping ${ }^{2}$ and Zhang Wenfeng ${ }^{2}$ \\ ${ }^{1}$ Department of Emergency and Department of Intensive Care Unit, The First Affiliated Hospital of Chongqing Medical \\ University, Chongqing 400010, P.R. China \\ ${ }^{2}$ Chongqing Key Laboratory of Hepatobiliary Surgery and Department of Hepatobiliary Surgery, The Second Affiliated Hospital \\ of Chongqing Medical University, Chongqing 400010, P.R. China \\ ${ }^{3}$ Department of Anesthesia, The Second Affiliated Hospital of Chongqing Medical University, Chongqing 400010, P.R. China \\ ${ }^{4}$ Department of Endocrine and Breast Surgery, The First Affiliated Hospital of Chongqing Medical University, Chongqing \\ 400010, P.R. China \\ *These authors have contributed equally to this work \\ Correspondence to: Zhang Wenfeng, email: zhangwenfeng07@163.com \\ Keywords: sepsis, stress hyperglycaemia, forkhead box O3a, nuclear factor $\mathrm{KB}, \mathrm{Akt}$ \\ Received: March 17, $2017 \quad$ Accepted: June 29, $2017 \quad$ Published: August 07, 2017 \\ Copyright: Bailin et al. This is an open-access article distributed under the terms of the Creative Commons Attribution License 3.0 \\ (CC BY 3.0), which permits unrestricted use, distribution, and reproduction in any medium, provided the original author and source \\ are credited.
}

\section{ABSTRACT}

Objective: The levels of Foxo3a in the peripheral blood mononuclears cells (PBMCs) before and after treatment were detected in acute obstructive suppurative cholangitis (AOSC) patients to evaluate the associations between Foxo3a and stress hyperglycemia (SHG).

Methods: PBMCs were obtained from AOSC patients $(n=28)$ on admission (AP), from patients at 1 week after cure (RP) and from healthy volunteers $(H V)(n=14)$ to evaluate the relationship between the protein levels of Foxo3a and the serum levels of glucose. Signaling pathways, which link inflammation and glycometabolism, simultaneously affecting the expression of Foxo3a, were detected. In addition, cytokines were detected in PBMCs and AOSC mouse models, which were pre-treated with Foxo3a agonist.

Results: The levels of glucose and p-Foxo3a in the AP were significantly higher than those in the RP and HV, where as the levels of Foxo3a in the AP were lower than those in the RP and HV. Foxo3a levels in the AP normalized against RP were strongly negatively correlated with the glucose levels in the AP normalized against RP. The levels of sphingosine-1-phosphate receptor 2 (S1PR2) in the AP were higher than those in the RP and HV. In addition, inhibition of Foxo3a phosphorylation, coupled with the down-regulation of S1PR2, attenuated the LPS-induced inflammatory response in the PBMCs and AOSC mouse models.

Conclusions: Foxo3a is correlated with the dysregulation of glucose homeostasis in the pathogenesis of AOSC-induced sepsis by inhibiting the activation of PI3K/AktS1PR2 and NF-KB pathways, hinting at a switched role and therapeutic potentialities in the early stage of sepsis. 


\section{INTRODUCTION}

Acute obstructive suppurative cholangitis (AOSC) is one of the most important and direct causes of deaths in patients with biliary tract diseases [1-2]. Mechanical obstructions, such as biliary calculi, biliary ascariasis, and biliary tract tumor, block up the common bile duct, leading to suppurative infection and empyema; high biliary pressure leads to a large number of bacteria and lipopolysaccharide (LPS) translocation into the peripheral blood, further resulting in sepsis, which can cause a series of serious complications, such as septic shock and multiple organ failure [3-4]. Stress hyperglycemia (SHG), is believed to be associated with poor outcomes of AOSC, is usually accompanied by sepsis in the eruption stage because of severe dysregulation of body homeostasis and rapid secretion of pro-inflammatory cytokines [5-6]. In addition, bacteria and LPS translocate into the peripheral blood, further activating downstream nuclear factor $\kappa \mathrm{B}$ (NF-kB) via Toll-like receptors (TLRs) producing a large number of pro-inflammatory cytokines, such as tumor necrosis factor $\alpha$ (TNF $\alpha)$ [7-8]. Thus, the activation of $\mathrm{NF}-\mathrm{\kappa B}$ is link to the pathogenesis of sepsis.

Generally, the activation of NF- $\mathrm{kB}$ first requires phosphorylation and degradation of inhibitor of NF- $\mathrm{KB}$ $\alpha(\mathrm{I} \kappa \mathrm{B}-\alpha)$, which is an anchor on NF- $\kappa \mathrm{B}$ polymers [8-9]. $\mathrm{NF}-\kappa \mathrm{B}$ polymers are activated and enter the cell nucleus as soon as I $\kappa \mathrm{B}-\alpha$ is degraded, thus further promoting the transcription and expression of pro-inflammatory cytokines [10-11]. Therefore, inhibiting the phosphorylation of IкB is an effective means to block the secretion of the proinflammatory cytokines induced by bacteria and LPS.

Forkhead box O3a (Foxo3a) not only directly phosphorylates I $\mathrm{KB}$ but also functions in the activation of NF- $\mathrm{KB}$ pathway in the infection disease [12-13]. In addition, it is well known that the phosphatidyl iositol 3-kinase (PI3K)/Akt/Foxo3a axis plays a key role in the regulation of glucose uptake and metabolism. PI3K/Akt activation is essential for the degradation of IкB- $\alpha$ and the activation of NF- $\mathrm{kB}$ by sphingosine-1-phosphate (S1P) via sphingosine-1-phosphate receptor 2 (S1PR2) [14-15]. However, few studies have reported the roles of Foxo3a in the relationship with glucose homeostasis in AOSCinduced sepsis. Therefore, our experiment detected the expression changes in Foxo3a in the peripheral blood mononuclear cells (PBMCs) of patients with acute obstructive suppurative cholangitis (AOSC) and discussed the associations of Foxo3a and SHG in sepsis.

\section{RESULTS}

\section{General condition of patients}

Among all of the patients with AOSC ( $\mathrm{n}=28)$, 24 cases had typical Charcot's triad and 18 cases had typical Reynold's pentad. Twenty-three cases had secondary choledocholithiasis caused by gallstones including 4 cases of Mirziz's syndrome, 7 cases of hepatolithiasis, 3 cases of benign bile duct stenosis and 2 cases of common bile duct bottom expansion. All of the patients underwent emergency operations such as common bile duct exploration combined with $\mathrm{T}$ tube drainage, bile duct puncture, cholangiojejunostomy and hepatic lobectomy, as soon as they were diagnosed with AOSC. No deaths occurred during hospitalization (5-16 days), 7 cases suffered serious complications after surgery. All of the patients achieved clinical cure criteria. The clinical presentations and laboratory results of the patients were shown in Tables 1 and 2, respectively.

\section{Changes in glucose, LPS, TNF $\alpha$ and IFN $\gamma$}

The serum levels of glucose, LPS and TNF $\alpha$ in the acute phase (AP) were significantly higher than those in healthy volunteers (HV) and decreased to normal levels after surgery and anti-inflammation therapy (recovery phase (RP)) (Figure 1 and Supplementary Table 1). The levels of interferon $\gamma$ (IFN $\gamma$ ) in the AP were higher than those in HV, and the levels of IFN $\gamma$ in the RP were lower than those in the AP, but they were still higher than in the HV (Figure 1 and Supplementary Table1). The data showed that LPS infiltrated from the intestine to the circulation in the eruption stage of infection, resulting in an imbalance in and pro- and anti-inflammatory cytokines cytokines.

\section{Changes in expression of Foxo3a in PBMCs}

The protein levels of Foxo3a in AOSC patients in the AP were significantly lower than those in HV and increased to normal levels after treatment (Figure 2 and Supplementary Table 2). However, the expression of p-Foxo3a dramatically increased in the AP in AOSC patients, compared to those in the RP and HV (Figure 2 and Supplementary Table 2). In addition, Foxo3a was decreased in nuclei and p-Foxo3a increased around the nuclei of PBMCs after treatment with a lethal dose of LPS (Figure 3). These results showed that Foxo3a was involved in the early stage of AOSC-induced sepsis.

\section{Activation of the NF-אB and PI3K/Akt pathways in PBMCs}

The protein levels of $\mathrm{p}-\mathrm{I} \kappa \mathrm{B}-\alpha$ and $\mathrm{p}-\mathrm{NF}-\kappa \mathrm{B}$ p65 dramatically increased in the AP in AOSC patients and reduced to normal levels after treatment (Figure 4 and Supplementary Table 3), whereas the expression levels of p-PI3K, p-Akt and S1PR2 returned to thier former unexcited state (Figure 4 and Supplementary Table 3). The data showed that the NF- $\mathrm{KB}$ and PI3K/Akt pathways were involved in the pathogenesis of AOSC-induced sepsis. 
Table 1: The clinical presentation and management of patients

\begin{tabular}{|c|c|c|c|c|c|c|c|}
\hline Presentation & No. & Concomitant disease & No. & Management & No. & Complication & No. \\
\hline fever/chill & 25 & cardiac insufficiency & 2 & $\begin{array}{l}\text { drainage of common } \\
\text { bile duct }\end{array}$ & 13 & pneumonia & 4 \\
\hline Jaundice & 24 & $\begin{array}{l}\text { pulmonary } \\
\text { insufficiency }\end{array}$ & 1 & bile duct puncture & 4 & $\begin{array}{l}\text { effusion and infection } \\
\text { of liver cutting surface }\end{array}$ & 1 \\
\hline epigastric pain & 27 & renal insufficiency & 1 & cholangiojejunostomy & 6 & bile leakage & 2 \\
\hline cachexia & 18 & $\begin{array}{l}\text { cirrhosis combined } \\
\text { with HBV }\end{array}$ & 3 & subtotal gastrectomy & 17 & & \\
\hline lethargy/coma & 18 & $\begin{array}{l}\text { a history of biliary } \\
\text { disease }\end{array}$ & 21 & hepatic lobectomy & 5 & & \\
\hline nausea/vomiting & 15 & $\begin{array}{l}\text { a history of biliary } \\
\text { surgery }\end{array}$ & 7 & & & & \\
\hline abdominal distension & 11 & & & & & & \\
\hline diarrhea & 12 & & & & & & \\
\hline
\end{tabular}

Table 2: Characteristics of AOSC patients and healthy volunteers

\begin{tabular}{|c|c|c|c|c|c|}
\hline & \multicolumn{2}{|c|}{ AOSC } & HV & $\chi 2$ value & p value \\
\hline Count & \multicolumn{2}{|c|}{28} & 14 & - & - \\
\hline Age (years) & \multicolumn{2}{|c|}{$38.46 \pm 13.32$} & $36.86 \pm 9.59$ & 0.136 & 0.691 \\
\hline Gender (male/female) & \multicolumn{2}{|c|}{$12 / 16$} & $8 / 6$ & 0.764 & 0.382 \\
\hline Clinical index & $\mathbf{A P}$ & $\mathbf{R P}$ & HV & $\chi^{2}$ value & p value \\
\hline $\begin{array}{l}\text { WBC } \\
\left(\times 10^{9} / \mathrm{L}\right)\end{array}$ & $16.37 \pm 2.87$ & $9.22 \pm 1.99 *$ & $8.14 \pm 1.64 * *$ & 0.07 & $\begin{array}{l}* 0.00 \\
* * 0.00\end{array}$ \\
\hline $\begin{array}{l}\text { CRP } \\
(\mathrm{mg} / \mathrm{L})\end{array}$ & $66.24 \pm 21.25$ & $6.28 \pm 2.22 *$ & $5.26 \pm 1.61 * *$ & 0.00 & $\begin{array}{l}* 0.00 \\
* * 0.00\end{array}$ \\
\hline $\begin{array}{l}\text { Procalcitonim } \\
(\mathrm{ng} / \mathrm{mL})\end{array}$ & $0.96 \pm 0.36$ & $0.03 \pm 0.02 *$ & $0.03 \pm 0.01 * *$ & 0.00 & $\begin{array}{l}* 0.00 \\
* * 0.00\end{array}$ \\
\hline $\begin{array}{l}\text { Creatinine } \\
\text { (umol/L) }\end{array}$ & $168.11 \pm 28.51$ & $78.24 \pm 19.70 *$ & $68.05 \pm 8.55 * *$ & 0.00 & $\begin{array}{l}* 0.00 \\
* * 0.00\end{array}$ \\
\hline $\begin{array}{l}\text { BUN } \\
(\mathrm{mmol} / \mathrm{L})\end{array}$ & $12.87 \pm 2.41$ & $4.90 \pm 1.48$ & $4.81 \pm 1.11$ & 0.01 & $\begin{array}{l}* 0.00 \\
* * 0.00\end{array}$ \\
\hline $\begin{array}{l}\text { TBIL } \\
\text { (umol/L) }\end{array}$ & $141.96 \pm 39.31$ & $13.52 \pm 3.88 *$ & $9.66 \pm 4.29 * *$ & 0.00 & $\begin{array}{l}* 0.00 \\
* * 0.00\end{array}$ \\
\hline $\begin{array}{l}\mathbf{A L T} \\
(\mathrm{U} / \mathrm{L})\end{array}$ & $197.09 \pm 41.46$ & $25.52 \pm 7.53$ & $20.45 \pm 9.40$ & 0.00 & $\begin{array}{l}* 0.00 \\
* * 0.00\end{array}$ \\
\hline $\begin{array}{l}\mathbf{A S T} \\
(\mathrm{IU} / \mathrm{L})\end{array}$ & $212.02 \pm 38.24$ & $23.87 \pm 8.78$ & $20.94 \pm 7.79$ & 0.00 & $\begin{array}{l}* 0.00 \\
* * 0.00\end{array}$ \\
\hline $\begin{array}{l}\mathbf{A L P} \\
(\mathrm{IU} / \mathrm{L})\end{array}$ & $569.32 \pm 214.04$ & $124.29 \pm 36.60 *$ & $101.07 \pm 34.33 * *$ & 0.00 & $\begin{array}{l}* 0.00 \\
* * 0.00\end{array}$ \\
\hline $\begin{array}{l}\gamma \text {-GGT } \\
(\mathrm{U} / \mathrm{L})\end{array}$ & $119.08 \pm 26.48$ & $28.08 \pm 14.41$ & $21.02 \pm 10.45$ & 0.00 & $\begin{array}{l}* 0.00 \\
* * 0.00\end{array}$ \\
\hline
\end{tabular}

*, RP vs AP; **, HV vs AP. 

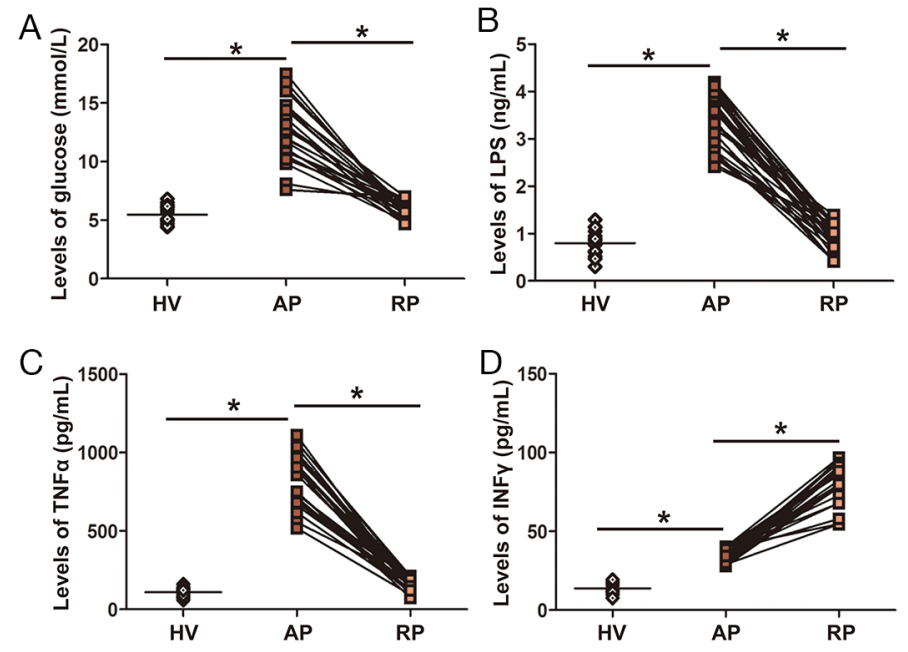

Figure 1: Serum levels of glucose, LPS, TNF $\boldsymbol{\alpha}$ and INF- $\boldsymbol{\gamma}$ in AOSC patients. (A) Serum levels of glucose in the AP were significantly higher than those in the RP and HV. (B) Serum levels of LPS in the AP were significantly higher than those in the RP and HV. (C) Serum levels of TNF $\alpha$ in the AP were significantly higher than those in the RP and HV. (D) Serum levels of INF- $\gamma$ in the AP were significantly lower than those in the RP, but higher than those in HV. *,$p<0.05$.

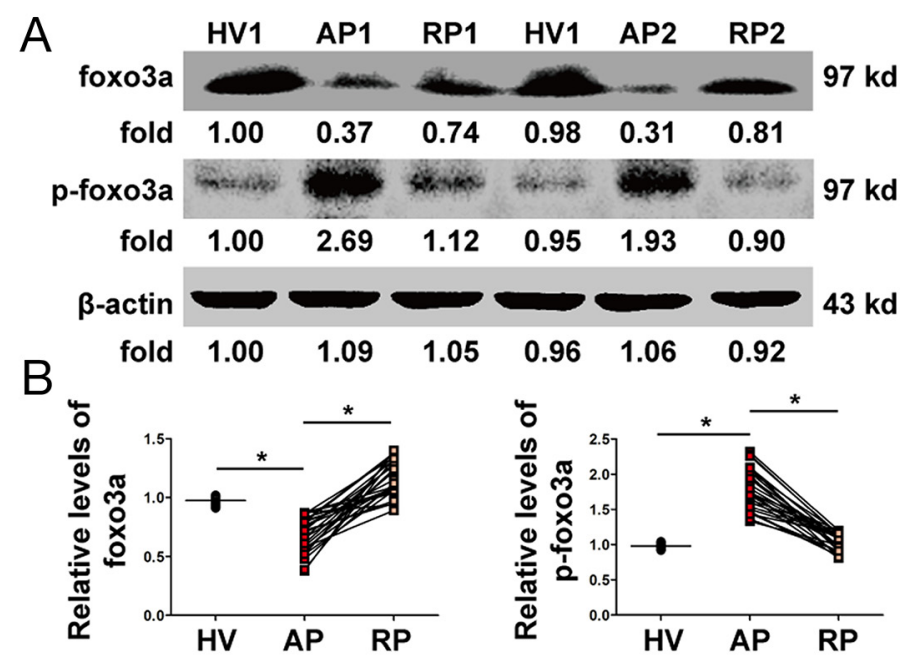

Figure 2: Changes in Foxo3a in PBMCs. (A) The expression and phosphorylation levels of Foxo3a were tested by WB in two patients before (AP) and after (RP) treatment and in one healthy volunteer (HV). (B) The protein levels of Foxo3a in AOSC patients in the AP were significantly lower than those in HV and were increased to normal levels after treatments, whereas the expression of p-Foxo3a increased dramatically in the AP in AOSC patients compared to those in the RP and HV. *,$p<0.05$.
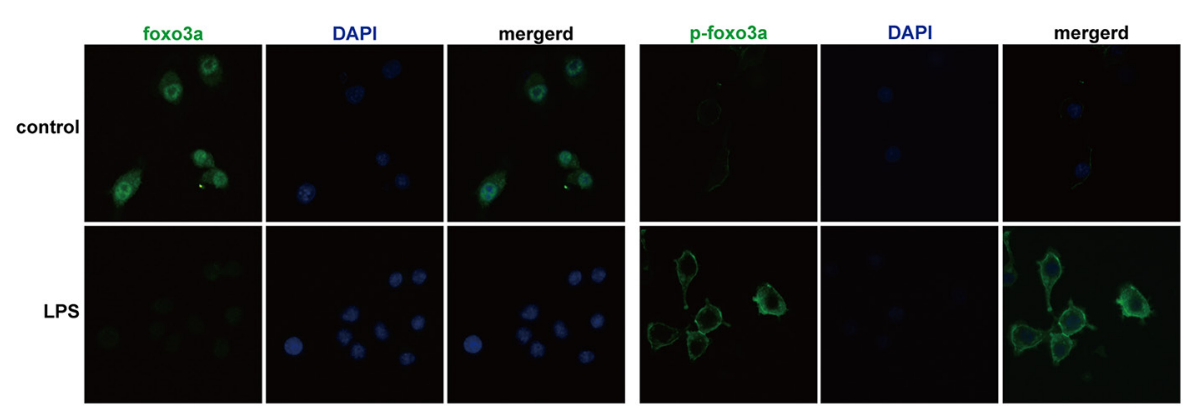

Figure 3: Foxo3a and p-Foxo3a levels in PBMCs were detected by immunofluorescence assay. Foxo3a was phosphorylated and discharged into the cytoplasm after stimulation by a lethal dose of LPS (100 ng/mL) (fluorescence microscope, FITC, 400×). 


\section{The relationship between Foxo3a and S1PR2 in PBMCs}

Foxo3a protein levels were increased by PI3K inhibitor (LY294002) in PBMCs. S1PR2 and TNF $\alpha$ induced by LPS were resisted by LY294002, while IFN $\gamma$ were increased by LY294002 in PBMCs (Figure 5A and $5 \mathrm{~B}$ ). At the same time, Foxo3a protein levels were inhibited by Akt agonist (SC79) in PBMCs. S1PR2 and TNF $\alpha$ induced by LPS were increased by SC79, whereas IFN $\gamma$ were decreased by SC79 in PBMCs (Figure 5C and 5D). Further, to validate the regulatory relation between Foxo3a of S1PR2, an inhibitor of S1PR2 (JTE013) was added into PBMC in vitro. The protein levels of S1PR2 were decreased by JTE-013, while the protein and phosphorylation levels of Foxo3a did not show any changes (Figure 5E). Similarly, the mRNA levels of TNF $\alpha$ and IFN $\gamma$ did not show any changes when PBMCs were stimulated by JTE-013 (Figure 5F). These results showed that inhibition of Foxo3a phosphorylation attenuated the LPS-induced inflammatory response by decreasing the expression of S1PR2.

\section{Correlation between of Foxo3a and SHG}

Foxo3a levels in the AP normalized against the RP were strongly negative correlated with glucose levels in the AP normalized against the RP, while p-Foxo3a levels in the AP normalized against the RP were positively correlated with glucose levels in the AP normalized against the RP (Figure 6). The data showed that the Foxo3a decrease was likely correlated with hyperglycemia in AOSC patients.

\section{Effect of Foxo3a in an AOSC mouse model}

The survival time of mice in the AOSC group was shorter than that in the AOSC+LY294002 group (Figure 7A). However, the overall survival rate showed no statistically difference between the AOSC group and the AOSC+LY294002 group. Similarly, clinical indices, such as C-reactive protein (CRP), procalcitonin, creatinine, urea nitrogen $(\mathrm{BUN})$, total bilirubin (TBIL), alanine transaminase (ALT), aspartate aminotransferase (AST), alkaline phosphatase (ALP), and glutamyltranspeptidase ( $\gamma$-GGT), in the peripheral blood of the AOSC group showed no differences as compared with those in the AOSC+LY294002 group (Table 3) after modeling of $24 \mathrm{~h}$. At the same time, serum levels of glucose and TNF $\alpha$ in the AOSC group were significant higher than those in the AOSC+LY294002 group, while the levels of IFN $\gamma$ were significantly lower than those in the AOSC+LY294002 group (Table 3 and Figure 7C). Similarly, the levels of p-Foxo3a and $\mathrm{S} 1 \mathrm{PR} 2$ in the peritoneal cells of the AOSC group were significantly higher than in the AOSC+LY294002 group, while the protein levels of Foxo3a were significantly lower than those in the AOSC+LY294002 group (Figure 7B). However, necrotic areas, inflammatory cells infiltration and biliary fibrosis were clearly observed
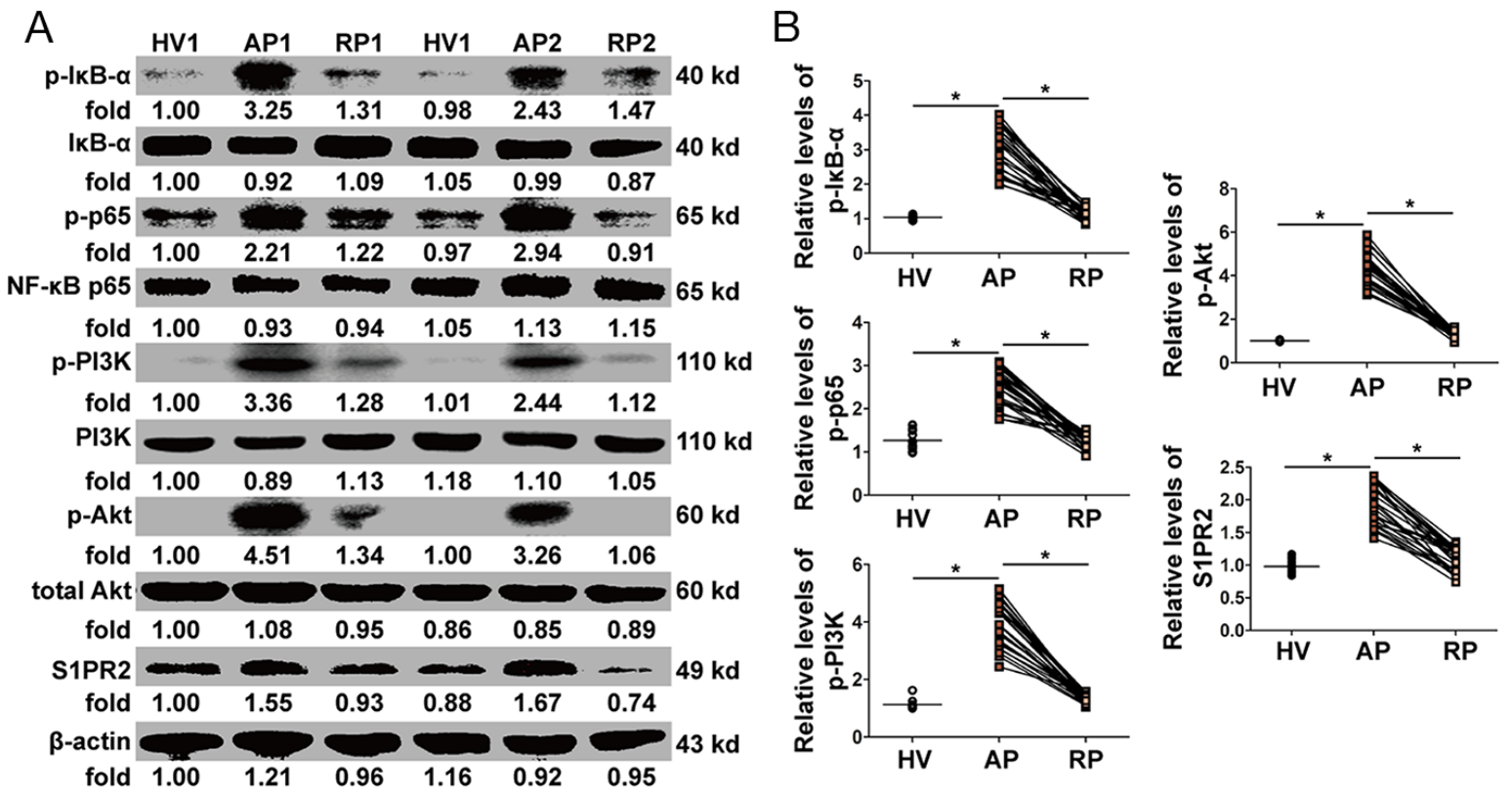

Figure 4: Activation of NF-KB and PI3K/Akt pathways in PBMCs. (A) The expression and phosphorylation levels of Foxo3a were tested by WB in two patients before (AP) and after (RP) treatment and in one healthy volunteer (HV). (B) The protein levels of

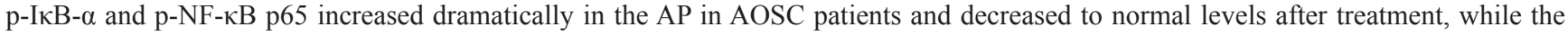
expression of p-PI3K, p-Akt and S1PR2 dramatically decreased after treatment. *, $p<0.05$. 


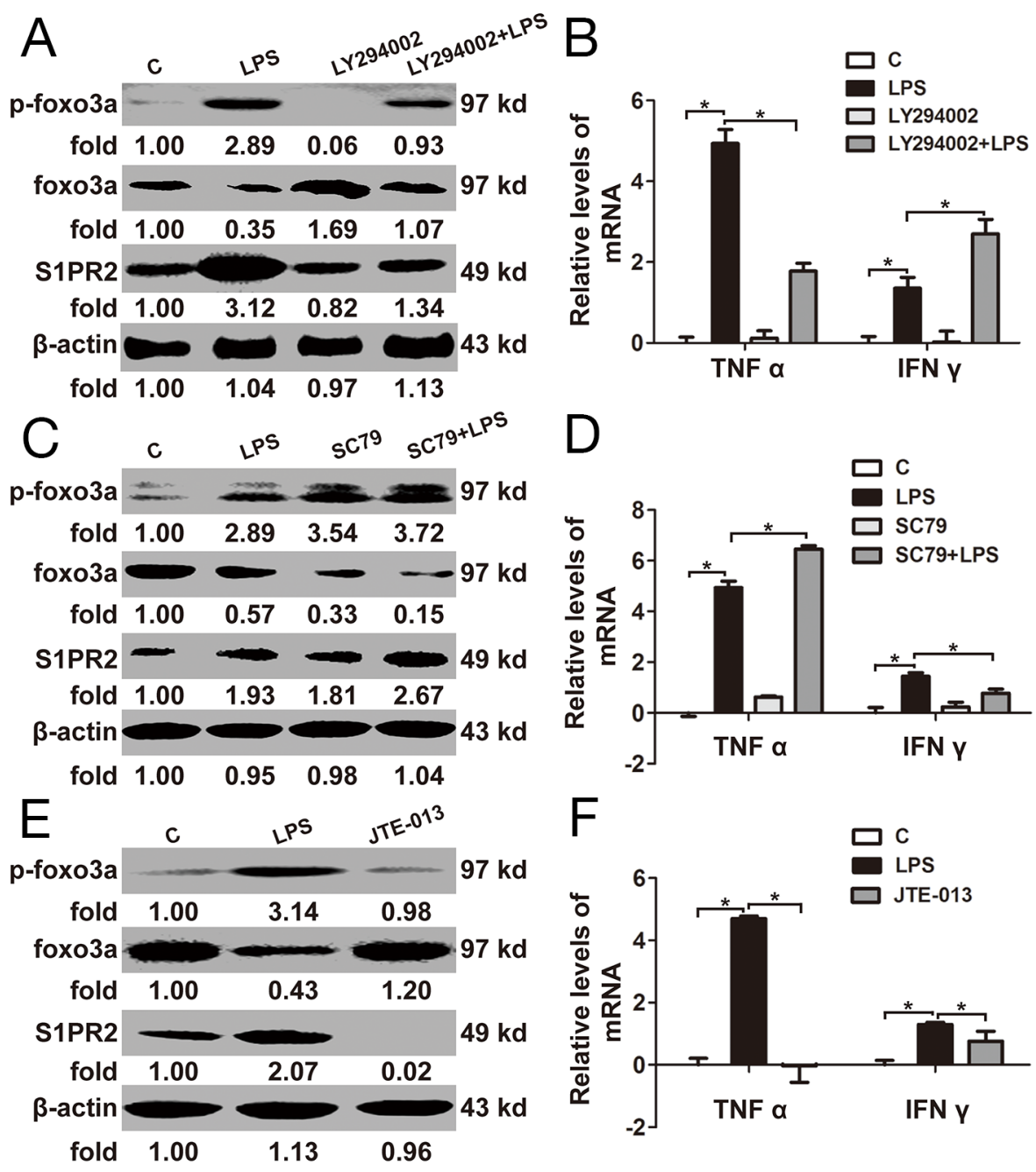

Figure 5: The relationship between Foxo3a and S1PR2 in PBMCs. (A) and (B) PBMCs were pre-treated with LY294002 for 1 $\mathrm{h}$ before stimulation with LPS for $2 \mathrm{~h}$ : the protein and phosphorylation levels of Foxo3a and S1PR2 were tested by WB assay; the mRNA levels of TNF $\alpha$ I and IFN $\gamma$ were detected by RT-PCR. (C) and (D) PBMCs were pre-treated with SC79 for $1 \mathrm{~h}$ before stimulation with LPS for $2 \mathrm{~h}$ : the protein and phosphorylation levels of Foxo3a and S1PR2 were tested by WB assay; the mRNA levels of TNF $\alpha$ and IFN $\gamma$ were detected by RT-PCR. (E) and (F) PBMCs were treated with LPS and JET-013 for $2 \mathrm{~h}$ : the protein and phosphorylation levels of Foxo3a and S1PR2 were tested by WB assay; the mRNA levels of TNF $\alpha$ and IFN $\gamma$ were detected by RT-PCR. *, $p<0.05$.
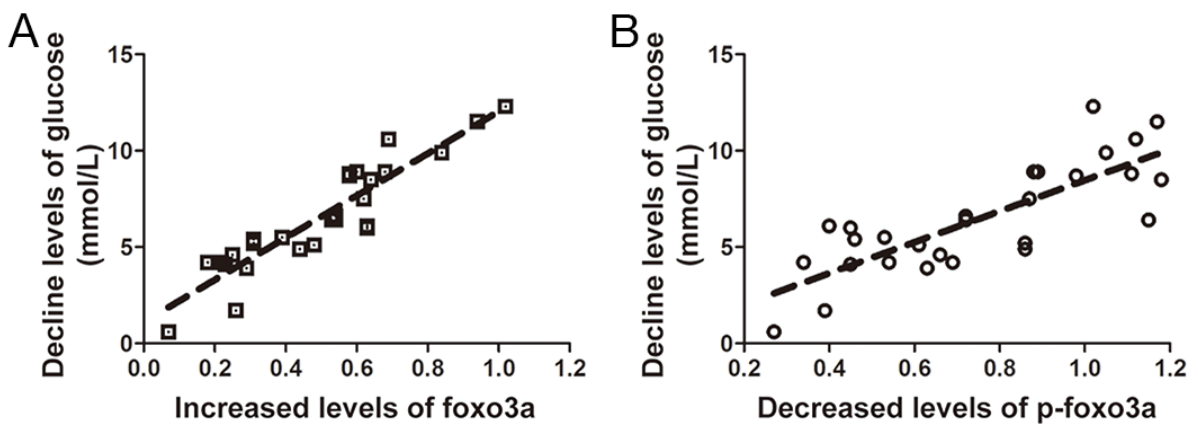

Figure 6: Correlation between expression and phosphorylation levels of Foxo3a and levels of glucose. (A) Foxo3a levels in the RP normalized against the AP were strongly positively correlated with the glucose levels in the AP normalized against the RP $\left(\mathrm{r}^{2}=0.845\right)$. (B) p-Foxo3a levels in the AP normalized against the RP were positive relates with the glucose levels in the AP normalized against the $\mathrm{RP}\left(\mathrm{r}^{2}=0.637\right)$. 
on histological examination of liver tissues in both the AOSC and AOSC+LY294002 groups (Figure 7D). These results indicated that inhibition of the phosphorylation of Foxo3a attenuated glucose levels and prolonged survival time by down-regulating the expression of SP1R2 to inhibit the secretion of pro-inflammatory cytokines in peritoneal cells in AOSC mouse models, although it had nothing to do with the mice's overall survival rate or physiological indices.

\section{DISCUSSION}

In this experiment, the variation in Foxo3a in PBMCs before and after treatment of AOCS patients was consistent with changes in LPS and inflammatory cytokines via the activation of $\mathrm{NF}-\kappa \mathrm{B}$ and PI3K/Akt. Inhibition of Foxo3a phosphorylation reduced the LPSinduced inflammation by down-regulating the expression of S1PR2 both in the PBMCs and in AOCS mouse models.
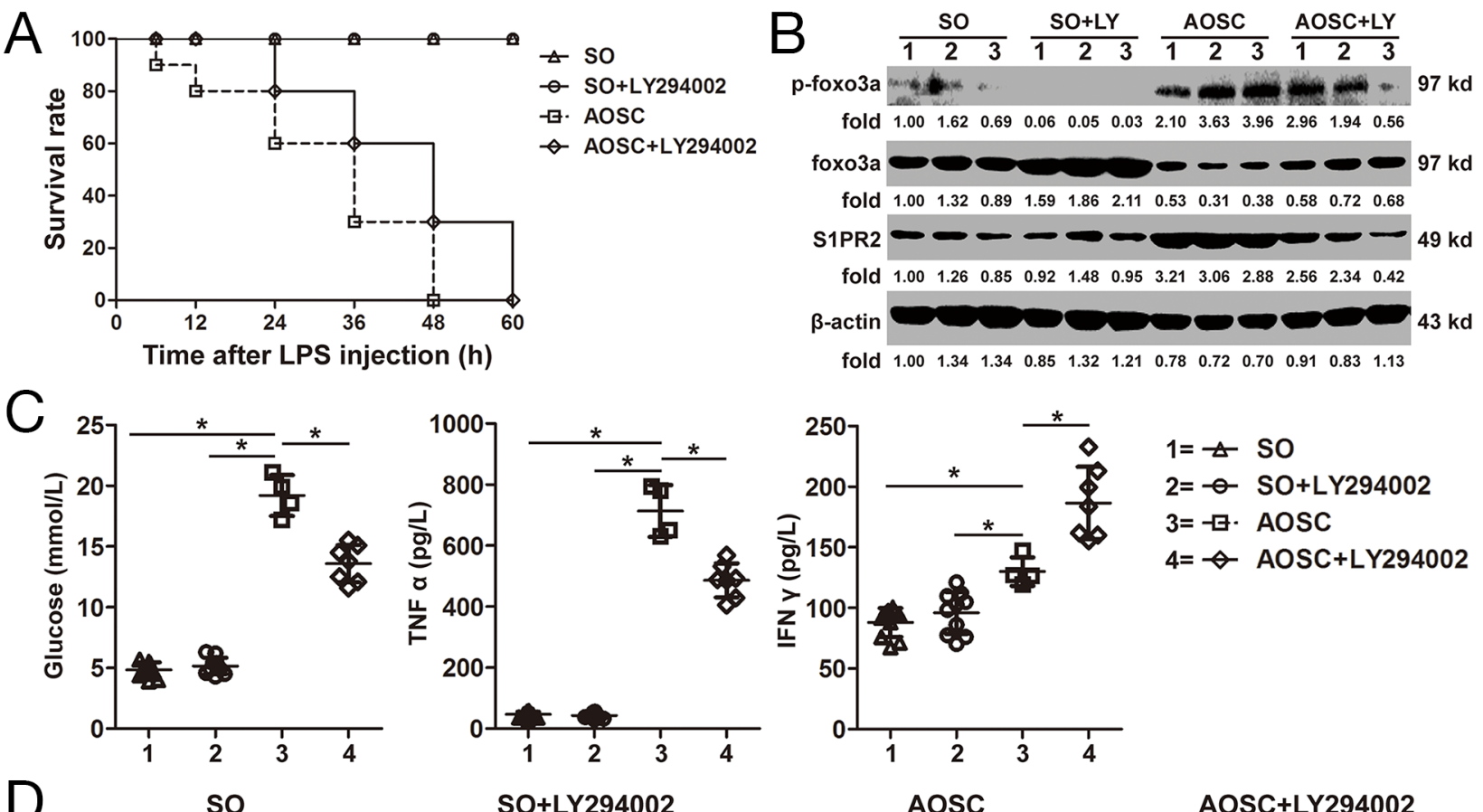

AOSC
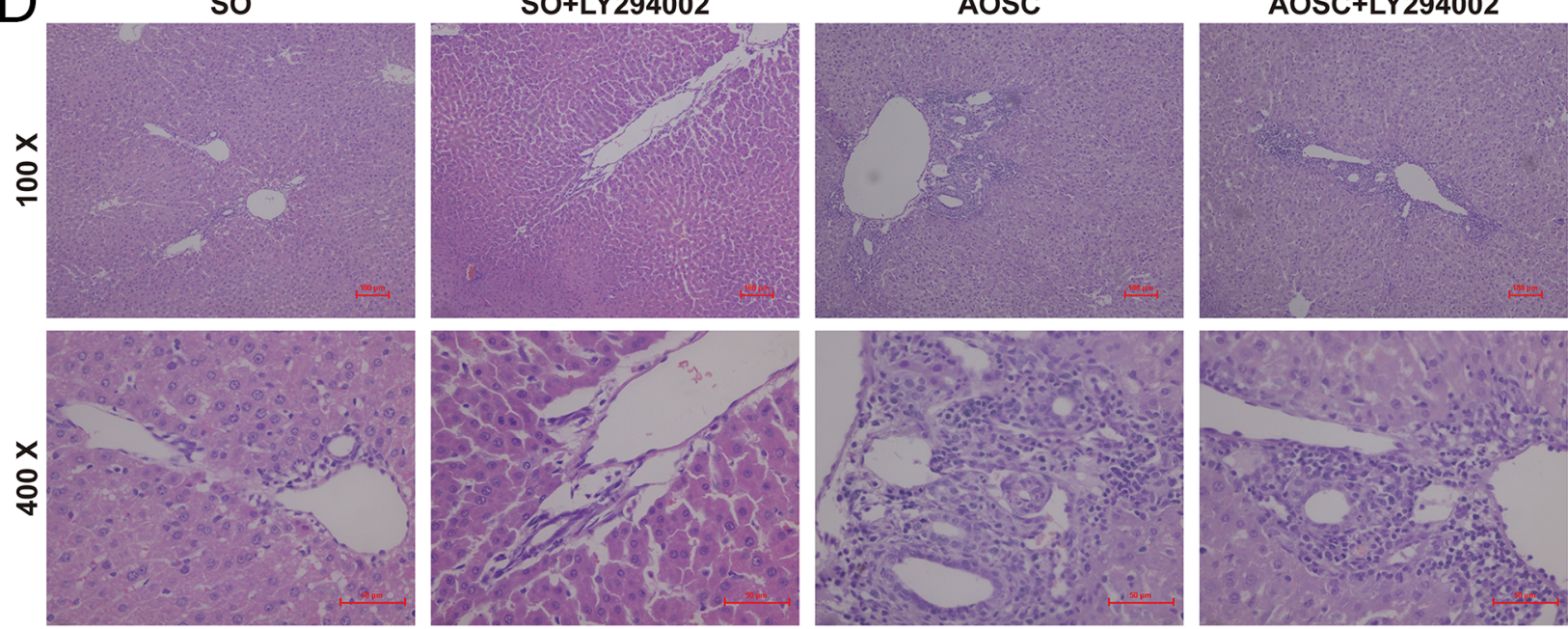

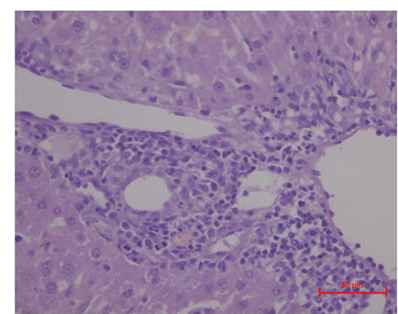

Figure 7: Effect of Foxo3a on AOSC mouse model. (A) Survival time of mice in the SO, SO+LY294002, AOSC and AOSC+LY294002 groups were observed at 6,12, 24, 48 and $60 \mathrm{~h}$ after LPS injection. (B) The protein and phosphorylation levels of Foxo3a and S1PR2 were tested by WB assay in peritoneal cells in the SO $(n=10)$, SO+LY294002 $(n=10)$, AOSC $(n=4)$ and AOSC + LY294002 $(n=4)$ groups at $24 \mathrm{~h}$ after LPS injection. (C) The serum levels of glucose, TNF $\alpha$ and IFN $\gamma$ were tested by ELISA in the SO ( $\mathrm{n}=10$ ), SO+LY294002 $(\mathrm{n}=10), \operatorname{AOSC}(\mathrm{n}=4)$ and AOSC+LY294002 $(\mathrm{n}=4)$ groups at $24 \mathrm{~h}$ after LPS injection. (D) The HE staining of liver tissue in the SO ( $=10)$, SO+LY294002 $(n=10), \operatorname{AOSC}(n=4)$ and AOSC+LY294002 $(n=4)$ groups at $24 \mathrm{~h}$ after LPS injection, $(100 \times$ and $400 \times) . *, p<0.05$. 
Table 3. Clinical indices in mouse model of AOSC

\begin{tabular}{|c|c|c|c|c|}
\hline Index & $\begin{array}{c}\text { SO } \\
(n=10)\end{array}$ & $\begin{array}{c}\text { SO+ LY294002 } \\
(n=10)\end{array}$ & $\begin{array}{c}\text { AOSC } \\
(n=4)\end{array}$ & $\begin{array}{c}\text { AOSC }+ \text { LY294002 } \\
(n=7)\end{array}$ \\
\hline $\mathrm{CRP}(\mathrm{mg} / \mathrm{L})$ & $2.81 \pm 0.66^{*}$ & $3.26 \pm 0.67 * *$ & $48.14 \pm 11.32$ & $40.07 \pm 16.34$ \\
\hline Procalcitonim (ng/mL) & $0.35 \pm 0.09 *$ & $0.33 \pm 0.06^{* *}$ & $2.52 \pm 0.20$ & $2.08 \pm 0.26$ \\
\hline Creatinine (umol/L) & $47.74 \pm 4.25^{*}$ & $45.18 \pm 4.48 * *$ & $167.65 \pm 19.20$ & $162.75 \pm 28.80$ \\
\hline BUN (mmol/L) & $6.18 \pm 1.05^{*}$ & $6.15 \pm 1.12^{* *}$ & $21.97 \pm 5.11$ & $23.39 \pm 3.57$ \\
\hline TBIL (umol/L) & $10.59 \pm 2.97 *$ & $10.07 \pm 3.14 * *$ & $160.75 \pm 29.54$ & $170.83 \pm 32.51$ \\
\hline $\operatorname{ALT}(\mathrm{U} / \mathrm{L})$ & $27.00 \pm 6.01 *$ & $28.71 \pm 6.90 * *$ & $290.07 \pm 38.66$ & $285.12 \pm 71.08$ \\
\hline AST (IU/L) & $97.65 \pm 8.31 *$ & $104.86 \pm 8.78 * *$ & $1052.77 \pm 180.85$ & $1006.19 \pm 132.00$ \\
\hline ALP (IU/L) & $108.98 \pm 13.39 *$ & $111.02 \pm 12.48 * *$ & $1550.83 \pm 181.53$ & $1765.73 \pm 330.16$ \\
\hline$\gamma-\mathrm{GGT}(\mathrm{U} / \mathrm{L})$ & $20.06 \pm 4.13 *$ & $19.05 \pm 4.88 * *$ & $94.71 \pm 11.74$ & $100.59 \pm 11.38$ \\
\hline Glucose $(\mathrm{mmol} / \mathrm{L})$ & $4.85 \pm 0.62 *$ & $5.17 \pm 0.68 * *$ & $19.20 \pm 1.68$ & $13.59 \pm 1.54 * * *$ \\
\hline $\mathrm{TNF} \alpha(\mathrm{pg} / \mathrm{mL})$ & $46.73 \pm 8.84^{*}$ & $42.87 \pm 8.42 * *$ & $713.83 \pm 85.06$ & $486.10 \pm 56.05 * * *$ \\
\hline $\operatorname{IFN} \gamma(\mathrm{pg} / \mathrm{mL})$ & $87.93 \pm 11.87 *$ & $95.93 \pm 17.34 * *$ & $130.06 \pm 11.80$ & $186.62 \pm 29.73 * * *$ \\
\hline
\end{tabular}

In addition, the Foxo3a decrease was likely related to hyperglycemia in AOSC patients. Thus, Foxo3a was a negative regulatory factor in the pathogenesis of AOCSinduced sepsis.

As we known, SHG induced by glucocorticoids and catecholamine is a typical complication of sepsis and is closely related to prognosis [16-17]. Larger amounts of pro-inflammatory cytokines, such as TNF $\alpha$ evoked by LPS, not only induce DNA damage in $\beta$ cells by directly promoting the expression of cyclic guanosine monophosphate (cGMP) but also inhibit the secretion of insulin by inducing the synthesis of inducible nitric oxide synthase (iNOS) [18-19]. In addition, TNF $\alpha$ blocks insulin signaling and glucose transport by inhibiting the tyrosine phosphorylation of insulin receptor substrates (IRS-1) and decreasing the expression of glucose transporter 4 (GLUT-4) [20]. Increased levels of TNF $\alpha$ and glucose were observed both in the immunocytes of AOSC patients and mouse models in this study. Thus, uncontrolled release of pro-inflammatory cytokines induced by LPS is a major factor that leads to insulin resistance and $\mathrm{SHG}$.

The NF- $\kappa \mathrm{B}$ pathway is one of the main mechanisms for secreting large numbers of pro-inflammatory cytokines, such as TNF $\alpha$, worsening the systemic inflammatory response in sepsis [21-22]. In addition, levels of IFN $\gamma$ returned to relatively low levels after cure; however, the levels of IFN $\gamma$ in the RP remained slightly higher than those in HV. IFN $\gamma$ was reported to restore partially aerobic glycolysis and to decrease mortality during the late phase of sepsis [23]. SHG is a result of an imbalance in proand anti-cytokines in the cytokine storm phase, in which the immune systems are disabled and immunocytes shift their glucose metabolism patterns [24-25]. Shang et al. asserted that p-Foxo3a phosphorylates I $\mathrm{B}-\alpha$ to activate $\mathrm{NF}-\kappa \mathrm{B}$ pathway when macrophages are irrigated by LPS [26]. Thompson et al. insisted that Foxo3a resists the

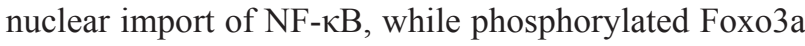
directly activates NF- $\kappa \mathrm{B}$ to promote the secretion of TNF $\alpha$ when pro-inflammatory cells are stimulated by bacteria or LPS [27]. In addition, phosphorylation of Foxo3a was affected by PI3K/Akt activation caused by infection or higher levels of blood glucose [28]. The data in this study also showed that PI3K inhibitor restrained Foxo3a phosphorylation to decrease the secretion of TNF $\alpha$ in both the PBMCs and AOSC mouse models. Thus, at least in this experiment, the Foxo3a decrease worsened the SHG in AOSC patients.

Foxo3a is one of the transcription factors in the forkhead box family, as well as a downstream molecule of the PI3K/Akt signaling pathways [29-30]. Phosphorylated Foxo3a escapes from DNA-binding sites and discharges into the cytoplasm to reduce its transcriptional activity as soon as the PI3K/Akt pathway is activated by exogenous irritants [31]. In addition, Foxo3a inhibits the generation of pro-inflammatory cytokines, such as TNF $\alpha$ and IL-6 in LPS-induced PBMCs [32]. Under a lethal dose of LPS stimulation, the expression of Foxo3a in PBMCs declined sharply, along with increased levels of TNF $\alpha$ in PBMCs [33]. Consistently, in this study, the Foxo3a decrease is not only caused by LPS translocation, but it also resulted in hyperglycemia induced by an uncontrolled release of proinflammatory cytokines. Thus, Foxo3a alleviates SHG in AOSC-induced sepsis by damping a cytokine storm.

Another cellular messenger, S1PR2, is the most important receptor for $\mathrm{S} 1 \mathrm{P}$ in macrophages and was 
Table 4: The inclusion, exclusion and recovery criteria

\section{Inclusion criteria}

Diagnosed and hospitalized at the Second Affiliated Hospital of Chongqing Medical University.

Aged between 18-70 years old.

Patients who had the pathological basis of cholangitis and common bile duct obstruction with operation indications of common bile duct drainage based on Tokyo Guidelines.

Clinical manifestation conforms to the guidelines for management of severe sepsis and septic shock [46].

Exclusion criteria

Patients conform to the inclusion criteria but refused to experimental arrangement.

Patients were older than 70 or younger than 18 year old.

AOSC was caused by tumor or congenital sclerosing cholangitis.

Patients have received anti-infective therapy or relieved biliary obstruction before admission.

Patients have surgical contraindications or major organs disease such as severe heart diseases, pneumonosis, renal failure that cannot tolerate the biliary puncture, biliary tract surgery or local and general anesthesia.

Patients had a history of diabetes or had been diagnosed for diabetes during hospitalization.

\section{Criteria for Recovery}

Biliary obstruction was completely relieved.

Hematological index return to normal levels.

Clinical symptoms of biliary obstruction or sepsis completely faded.

positively correlated with the severity of sepsis [34-35]. $\mathrm{S} 1 \mathrm{PR} 2$ has been reported to induce $\mathrm{NF}-\kappa \mathrm{B}$ activation by promoting the phosphorylation of PI3K/Akt [36-37]. Cui et al. reported that S1PR2 protects against anaphylactic shock by inhibiting the synthesis of endothelial nitric oxide [38]. Yang et al. asserted that S1PR2/3 accelerates liver injury in mouse models of bile duct ligation by promoting the motility of bone marrow-derived macrophages and inspiring pro-inflammatory cytokines by activating the pertussis toxin/PI3K/Rac1 signaling pathway [39]. In our study, S1PR2 in the AP was significantly higher than in the RP and HV. Suppression of Foxo3a phosphorylation down-regulated the expression of S1PR2 in PBMCs, while agitation of Foxo3a phosphorylation up-regulated the expression of S1PR2 in PBMCs. In addition, the expression of S1PR2 in peritoneal immune cells was inhibited by LY294002 which is an inhibitor of Foxo3a phosphorylation, leading to lower levels of TNF $\alpha$ and glucose, although these outcomes were not related to the overall survival of AOSC mouse models. Thus, this study is the first time to report that Foxo3a is a negative regulator of S1PR2 for inspiring AOSC-induced sepsis.

In conclusion, Foxo3a was correlated with the dysregulation of glucose homeostasis in the pathogenesis of AOSC-induced sepsis by inhibiting activation of the PI3K/ Akt-S1PR2 and NF- $\kappa$ B pathways, hinting at a switched role and therapeutic potentiality in the early stage of sepsis.

\section{MATERIALS AND METHODS}

\section{Patients}

All of the patients with AOSC were diagnosed and hospitalized in the Second Affiliated Hospital of Chongqing Medical University from January 2015 to June 2016. Diagnosis was subject to magnetic resonance cholangiopancreatography (MRCP) or computer tomography (CT) combined with clinical manifestations and serological test results. Patients were jointly diagnosed by 3 doctors with more than 20 years of clinical experience in hepatobiliary surgery, based on Tokyo Guidelines [40]. All of the patients routinely received cefotiam hydrochloride $(1.0 \mathrm{~g})$, polyene phosphatidyl choline $(465 \mathrm{mg})$ and glutathione $(1.2 \mathrm{~g})$ twice per day for 3-5 d after surgery. The inclusion, exclusion and recovery criteria are shown in Table 4.

\section{Healthy volunteers}

Volunteers were recruited from regular checkups at the Second Affiliated Hospital of Chongqing Medical University from January 2014 to June 2016. People with tumors or infectious diseases or who did not agree with our experimental arrangement was excluded. Healthy volunteers and patients were matched at a 1:2 ratio. 


\section{Ethics, consent and permissions}

All of the recruited participants including AOSC patients and healthy volunteers were well informed of our experimental plans. All of the recruited participants agreed to our experimental arrangement, and all participants with informed consent donated their blood for this study. In addition, this study was approved by the Ethics Committee of the Second Affiliated Hospital of Chongqing Medical University. All of the operations for AOSC patients and healthy volunteers in this study strictly conformed to the World Medical Association's Declaration of Helsinki.

\section{Separation of PBMCs}

A total of $25 \mathrm{ml}$ peripheral blood was collected from each AOSC patient as soon as admission (AP) and 1 week after cure (RP). The serum was separated from samples by density gradient centrifugation ( $2000 \mathrm{r} / \mathrm{min}, 10 \mathrm{~min}$ ) for enzyme linked immunosorbent assay (ELISA) detection. The residual blood cells were mixed with an equal volume of phosphate buffer solution (PBS) $(0.01 \mathrm{M}, \mathrm{pH}=7.4)$ and were placed in a centrifuge tube; then, an equal volume of peripheral blood separation liquid (LDS1075, Jingyang, Tianjin China) was gently added in the mixture and allowed to stand for $5 \mathrm{~min}$ before horizontal density gradient centrifugation ( $400 \mathrm{~g}, 20 \mathrm{~min}$ ). The mononuclear cells were extracted after centrifugation and washed with $10 \mathrm{ml}$ of PBS twice ( $300 \mathrm{~g}, 10 \mathrm{~min}$ ). Finally, the obtained PBMCS were extracted for total protein. Each healthy volunteer underwent collection of a total of $25 \mathrm{ml}$ of blood as soon as admission (HV), which handled with the aforementioned procedures.

\section{Cultivation and treatment of PBMCs}

PBMCs separated from healthy volunteers with the above procedures were cultured with medium containing $10 \%$ fetal bovine serum in an incubator under conditions of $37^{\circ} \mathrm{C}, 5 \% \mathrm{CO}_{2}$ and appropriate humidity. After $6 \mathrm{~h}$ of cultivation, the medium was replaced to remove the nonadherent cells. The adherent cells continued to cultivate for $12 \mathrm{~h}$. Then, PBMCs were pretreated with LY294002 $(30 \mu \mathrm{M})(\mathrm{S} 1105$, Selleck, USA) and SC79 $(4 \mu \mathrm{g} / \mathrm{ml})(\mathrm{S} 7863$, Selleck, USA) for $1 \mathrm{~h}$, followed by treatment with LPS $(100 \mathrm{ng} / \mathrm{ml})(\mathrm{L} 5293$, SIGMA, USA) for $2 \mathrm{~h}$. For S1PR2 inhibitor testing, PBMCs were pretreated with JET-013 $(1 \mu \mathrm{M})(\mathrm{S} 7182$, Selleck, the USA) and LPS $(100 \mathrm{ng} / \mathrm{ml})$ for $2 \mathrm{~h}$. The total protein and RNA of PBMCs were collected for western blotting (WB) and real-time polymerase chain reaction (RT-PCR). Safe doses of LY294002, SC79 and JET-013 were verified in previous studies [39, 41-42].

\section{Immunofluorescence assay}

The PBMCs were grown on slides pre-treated with LPS $(100 \mathrm{ng} / \mathrm{ml})$ for $2 \mathrm{~h}$ and were treated with $0.1 \%$ Triton
(ST795, Beyotime, China) for $10 \mathrm{~min}$ at room temperature after being fixed using $4 \%$ paraformaldehyde at $4{ }^{\circ} \mathrm{C}$, following by blocking with $5 \%$ goat serum for $1 \mathrm{~h}$ at room temperature. The cells were stained with primary antibody at $4{ }^{\circ} \mathrm{C}$ overnight and then were incubated with secondary antibodies labeled with fluorescein isothiocyanate (FITC) for $60 \mathrm{~min}$ at room temperature, followed by 4,6-diamidino-2-phenylindole dihydrochloride (DAPI) for nuclear staining for $2 \mathrm{~min}$. Then, the slides were observed using a fluorescence microscope in dark phase with a 488 $\mathrm{nm}$ radial. The antibodies used in the assay are showed in Supplementary Table 4.

\section{Animals and AOSC mouse models}

Male C57BL/6 mice (pathogen-free, 20-22 g, 8 weeks old) were purchased from the Experimental Animal Center of Chongqing Medical University (Chongqing, China). All surgeries on the mice obtained permission from the Ethics Committee of Chongqing Medical University. The mice received good, humane care before and after modeling.

The AOSC mouse models were created according to previous reports with slight changes [43]. Briefly, after an overnight fast, the mice were first anesthetized, and the common bile duct was dissociated and ligated. Then, the mice underwent cholecystostomy by an epidural catheter fixed in the backs of the mice. LPS in a volume of $0.5 \mathrm{ml}$ $(10 \mathrm{mg} / \mathrm{kg})$ was injected immediately into the gallbladder through the epidural catheter. Then, the epidural catheter was sealed, and the mice were observed until mortality after injection of LPS. All of the surgeries were performed under $40 \mathrm{mg} / \mathrm{kg} 1 \%$ pentobarbital sodium salt to minimize suffering.

\section{Experimental groups}

For survival testing, 40 mice were randomly divided into 4 groups: the sham-operation group (SO group), in which the mice received simple laparotomy surgery; the sham-operation combined with LY294002 treatment group (SO+LY294002 group), in which the mice were intraperitoneally pre-injected with LY294002 $(5 \mathrm{mg} / \mathrm{kg})$ for $6 \mathrm{~h}$ before laparotomy surgery; the AOSC mouse model group (AOSC group), in which the mice were modeled for AOSC using the above procedures; and the AOSC mouse model combined with LY294002 treatment group (AOSC+LY294002 group), in which the mice were pretreated with intraperitoneal injection of LY294002 $(5 \mathrm{mg} /$ $\mathrm{kg}$ ) for $6 \mathrm{~h}$ before submission to a AOSC model. All of the mice were observed for their survival state after surgery at $6,12,24,48$ and $60 \mathrm{~h}$. The safe and effective dose ranges of LY294002 were previously determined [44].

Another 40 mice were randomly divided into 4 groups as described above. The mice were sacrificed to collect peritoneal cells, serum and liver tissue at $24 \mathrm{~h}$ 
after surgery. The numbers of surviving mice in the $\mathrm{SO}$, SO+LY294002, AOSC and AOSC+LY294002 groups were $10,10,4$ and 7 , respectively.

\section{Isolation of peritoneal cells}

Peritoneal cells were isolated according to the previous report [45]. Briefly, the mice were first euthanized, and the peritoneum was exposed immediately after abdominal disinfection. PBS in a volume of $5 \mathrm{ml}$ was injected into the peritoneal cavity, and the peritoneum was gently massaged for $5 \mathrm{~min}$. The fluid was collected as much as possible, following by centrifugation at $1500 \mathrm{rpm}$ for $8 \mathrm{~min}$, the residual cells were extracted for total protein.

\section{Western blotting assay}

Total proteins were extracted from $1 \times 10^{6}$ cells with $100 \mu \mathrm{l}$ of RIPA (AR0105, Boster, Wuhan China) lysis buffer. The concentration of protein was tested using a BCA kit (AR0146, Boster, Wuhan China) and $50 \mu \mathrm{g}$ of total protein were separated by $10 \%$ SDS-PAGE $(100 \mathrm{~V}$, $120 \mathrm{~min}$ ) and then were blotted to polyvinylidene fluoride (PVDF) membranes (250 mA, 90-60 min). Bovine serum albumin at a concentration of 5\% was used to block the PVDF membranes for $90 \mathrm{~min}$ at room temperature. Then the membranes were incubated with primary antibodies over night at $4{ }^{\circ} \mathrm{C}$, followed by incubation with horseradish peroxidase conjugated anti-IgG secondary antibodies at $37^{\circ} \mathrm{C}$ for $1.5 \mathrm{~h}$. Finally, the PVDF membranes were visualized using the Chemico-EQ system (Bio-Rad, USA). The values of targeted protein bands were detected using Image Lab 4 software (Bio-Rad, USA) and were normalized against $\beta$-actin values. The antibodies used in the WB assay are shown in Supplementary Table 4.

\section{RT-PCR analysis}

Total RNA was extracted from $1 \times 10^{6}$ PBMCs using an ultrapure RNA kit (CW0597, cwbiotech, China). The RNA samples were reverse transcribed into cDNA using a Primescript ${ }^{\mathrm{TM}}$ RT Reagent Kit with gDNA Eraser (RR047A; Takara Biotechnology, Japan), strictly according to the protocols of the manufacturer. The relative expression levels of the target genes were determined using the -Delta Delta $\mathrm{C}(\mathrm{T})$ method after normalizing against the GADPH gene. The primers were showed at Supplementary Table 4.

\section{ELISA}

The serum levels of LPS (xy-0784E, Xinyu, Shanghai), TNF $\alpha$ (EK0525, Boster, Wuhan China) and IFN $\gamma$ (KHC4021, Thermo Fisher, the USA) were quantified using commercially available ELISA kits.
All of the operations were in strict accordance with the manufacturer's instructions.

\section{Statistical analysis}

All of the measured data in this study were subject to normal distributions, which were analyzed by the Kolmogorov-Smirnov test. Data were expressed as $\bar{x} \pm \mathrm{s}$ and were analyzed with SPSS software (version 18.0). Data from multiple groups were compared with ANOVA, and two independent samples underwent the applied comparative t-test to perform statistical analysis. Categorical data were analyzed using the Chi-Square test. To test for correlations, Pearson's simple correlation coefficient or Spearman's rank correlation coefficient was applied. $\mathrm{p}$ values less than 0.05 were considered to indicate statisticallysignificant differences.

\section{Abbreviations}

ALP: alkaline phosphatase

ALT: alanine transaminase

AOSC: acute obstructive suppurative cholangitis

AOSC group: AOSC mice models group

AOSC+LY294002 group: AOSC mice models

combined with LY294002 treatment group

AP: acute phase

AST: aspartate aminotransferase

BUN: blood urea nitrogen

cGMP: cyclic guanosine monophosphate

CRP: C-reactive protein

CT: computer tomography

DAPI: 4,6-diamidino-2-phenylindole

dihydrochloride

ELISA: enzyme linked immunosorbent assay

FITC: fluorescein isothiocyanate

Foxo3a: forkhead box O3a

GADPH: glyceraldehyde-3-phosphate

dehydrogenase

$\gamma$-GGT: glutamyltranspeptidase

GLUT-4: glucose transporter 4

$\mathrm{HV}$ : healthy volunteers

IFN $\gamma$ : interferon $\gamma$

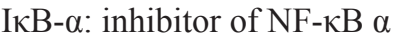

iNOS: inducible nitric oxide synthase

IRS-1: insulin receptor substrates

LPS: lipopolysaccharide

MRCP: cholangiopancreatography

NF- $\kappa B$ : nuclear factor $\kappa B$

PBMC: peripheral blood mononuclear

PBS: phosphate buffer solution

PI3K: phosphatidyl iositol 3-kinase

PVDF: polyvinylidene fluoride

$R P$ : recovery phase

RT-PCR: real time polymerase chain reaction 
S1PR2: sphingosine-1-phosphate (S1P) via

sphingosine-1-phosphate receptor 2

SHG: stress hyperglycaemia

SO group: sham-operation group

SO+LY294002 group: sham-operation combined

with LY294002 treatment group

TBIL: total bilirubin

WB: western blotting

\section{Author contributions}

Zhang Wenfeng and Gong Jianping designed this experiment. Zhang Wenfeng, Niu Bailin and Chen Nan performed the WB and completed the manuscript. Gong Jianping, Li Peizhi and He Kun performed the treatment of AOSC. Zhu Xiwen collected and analyzed the clinical data. Ren Guosheng and Zhang Wenfeng established the animal models. Gong Jianping further polished the manuscript. Zhang Wenfeng authorized publishing the manuscript.

\section{ACKNOWLEDGMENTS}

This study was performed by the Chongqing Key Laboratory of Hepatobiliary Surgery and the Department of Hepatobiliary Surgery of the Second Affiliated Hospital of Chongqing Medical University.

\section{CONFLICTS OF INTEREST}

The authors declare no conflicts of interest.

\section{FUNDING}

This work was supported by the National Natural Science Foundation of China (Nos. 31370753, 81401622, 81400614, 81601715) and the Fostering Foundation of the First Affiliated Hospital of Chongqing Medical University (PYJJ2017-26).

\section{REFERENCES}

1. Nagaraja V, Eslick GD, Cox MR. Systematic review and meta-analysis of minimally invasive techniques for the management of cholecysto-choledocholithiasis. J Hepatobiliary Pancreat Sci. 2014; 21: 896-901.

2. Tajima Y, Kuroki T, Susumu S, Tsutsumi R, Kitasato A, Adachi T, Mishima T, Kanematsu T. Acute suppuration of the pancreatic duct associated with pancreatic ductal obstruction due to pancreas carcinoma. Pancreas. 2006; 33: 195-7.

3. Yin P, Wang M, Qin R, Zhang J, Xiao G, Yu H, Ding Z, $\mathrm{Yu}$ Y. Intraoperative endoscopic nasobiliary drainage over primary closure of the common bile duct for choledocholithiasis combined with cholecystolithiasis: a cohort study of 211 cases. Surg Endosc. 2016.
4. Minaga K, Kitano M, Imai H, Yamao K, Kamata K, Miyata T, Omoto S, Kadosaka K, Yoshikawa T, Kudo M. Urgent endoscopic ultrasound-guided choledochoduodenostomy for acute obstructive suppurative cholangitis-induced sepsis. World J Gastroenterol. 2016; 22: 4264-9.

5. Shankar-Hari M, Phillips GS, Levy ML, Seymour CW, Liu VX, Deutschman CS, Angus DC, Rubenfeld GD, Singer M. Developing a new definition and assessing new clinical criteria for septic shock: for the third international consensus definitions for sepsis and septic shock (sepsis-3). JAMA. 2016; 315: 775-87.

6. Horn P, Metzing UB, Steidl R, Romeike B, Rauchfuß F, Sponholz C, Thomas-Rüddel D, Ludewig K, Birkenfeld AL, Settmacher U, Bauer M, Claus RA, von LC. Chemerin in peritoneal sepsis and its associations with glucose metabolism and prognosis: a translational cross-sectional study. Crit Care. 2016; 20: 39.

7. Pyle A, Ibbett IM, Gordon C, Keers SM, Walker M, Chinnery PF, Baudouin SV. A common UCP2 polymorphism predisposes to stress hyperglycaemia in severe sepsis. J Med Genet. 2009; 46: 773-5.

8. Anderson ST, Commins S, Moynagh PN, Coogan AN. Lipopolysaccharide-induced sepsis induces long-lasting affective changes in the mouse. Brain Behav Immun. 2015; 43: 98-109.

9. Liu Z, Shi Q, Liu J, Abdel-Razek O, Xu Y, Cooney RN, Wang G. Innate immune molecule surfactant protein D attenuates sepsis-induced acute pancreatic injury through

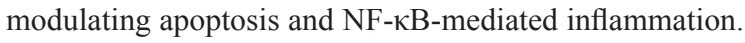
Sci Rep. 2015; 5: 17798.

10. Voss $\mathrm{OH}$, Murakami Y, Pena MY, Lee HN, Tian L, Margulies DH, Street JM, Yuen PS, Qi CF, Krzewski K, Coligan JE. Lipopolysaccharide-induced CD300b receptor binding to toll-like receptor 4 alters signaling to drive cytokine responses that enhance septic shock. Immunity. 2016; 44: 1365-78.

11. Huang W, Morales JL, Gazivoda VP, August A. Nonreceptor tyrosine kinases ITK and BTK negatively regulate mast cell proinflammatory responses to lipopolysaccharide. J Allergy Clin Immunol. 2016; 137: 1197-205.

12. Li K, Yang J, Han X. Ketamine attenuates sepsis-induced acute lung injury via regulation of HMGB1-RAGE pathways. Int Immunopharmacol. 2016; 34: 114-28.

13. Rackov G, Hernández-Jiménez E, Shokri R, CarmonaRodríguez L, Mañes S, Álvarez-Mon M, López-Collazo E, Martínez-A C, Balomenos D. p21 mediates macrophage reprogramming through regulation of p50-p50 NF- $\mathrm{kB}$ and IFN- $\beta$. J Clin Invest. 2016; 126: 3089-103.

14. Xu X, Liu N, Zhang YX, Cao J, Wu D, Peng Q, Wang HB, Sun WC. The protective effects of HJB-1, a derivative of 17-hydroxy-jolkinolide B, on LPS-induced acute distress respiratory syndrome mice. Molecules. 2016; 21: 77.

15. Kang DW, Park MK, Oh HJ, Lee DG, Park SH, Choi KY, Cho ML, Min dS. Phospholipase D1 has a pivotal role in 
interleukin- $1 \beta$-driven chronic autoimmune arthritis through regulation of $\mathrm{NF}-\kappa \mathrm{B}$, hypoxia-inducible factor $1 \alpha$, and FoxO3a. Mol Cell Biol. 2013; 33: 2760-72.

16. McClelland DD, Satoorian TS, Walker LM, Sparks NR, Pulyanina PY, Zur NNI. Glucose-induced oxidative stress reduces proliferation in embryonic stem cells via FOXO3A/ $\beta$-catenin-dependent transcription of $\mathrm{p} 21$ (cip1). Stem Cell Reports. 2016; 7: 55-68.

17. Gorbunov NV, Garrison BR, McDaniel DP, Zhai M, Liao PJ, Nurmemet D, Kiang JG. Adaptive redox response of mesenchymal stromal cells to stimulation with lipopolysaccharide inflammagen: mechanisms of remodeling of tissue barriers in sepsis. Oxid Med Cell Longev. 2013; 2013: 186795.

18. Montori VM, Bistrian BR, McMahon MM. Hyperglycemia in acutely ill patients. JAMA. 2002; 288: 2167-9.

19. Cohen $P$. The twentieth century struggle to decipher insulin signalling. Nat Rev Mol Cell Biol. 2006; 7: 867-73.

20. Hotamisligil GS, Peraldi P, Budavari A, Ellis R, White MF, Spiegelman BM. IRS-1-mediated inhibition of insulin receptor tyrosine kinase activity in TNF-alpha- and obesityinduced insulin resistance. Science. 1996; 271: 665-8.

21. Hawiger J, Veach RA, Zienkiewicz J. New paradigms in sepsis: from prevention to protection of failing microcirculation. J Thromb Haemost. 2015; 13: 1743-56.

22. Eisen DP. Manifold beneficial effects of acetyl salicylic acid and nonsteroidal anti-inflammatory drugs on sepsis. Intensive Care Med. 2012; 38: 1249-57.

23. Cheng SC, Scicluna BP, Arts RJ, Gresnigt MS, Lachmandas E, Giamarellos-Bourboulis EJ, Kox M, Manjeri GR, Wagenaars JA, Cremer OL, Leentjens J, van der Meer AJ, van de Veerdonk FL, et al. Broad defects in the energy metabolism of leukocytes underlie immunoparalysis in sepsis. Nat Immunol. 2016; 17: 406-13.

24. Vachharajani V, Liu T, McCall CE. Epigenetic coordination of acute systemic inflammation: potential therapeutic targets. Expert Rev Clin Immunol. 2014; 10: 1141-50.

25. Cheng SC, Joosten LA, Netea MG. The interplay between central metabolism and innate immune responses. Cytokine Growth Factor Rev. 2014; 25: 707-13.

26. Shang YC, Chong ZZ, Hou J, Maiese K. Wnt1, FoxO3a, and NF-kappaB oversee microglial integrity and activation during oxidant stress. Cell Signal. 2010; 22: 1317-29.

27. Thompson MG, Larson M, Vidrine A, Barrios K, Navarro F, Meyers K, Simms P, Prajapati K, Chitsike L, Hellman LM, Baker BM, Watkins SK. FOXO3-NF-кB RelA protein complexes reduce proinflammatory cell signaling and function. J Immunol. 2015; 195: 5637-47.

28. Ni YG, Wang N, Cao DJ, Sachan N, Morris DJ, Gerard RD, Kuro-O M, Rothermel BA, Hill JA. FoxO transcription factors activate Akt and attenuate insulin signaling in heart by inhibiting protein phosphatases. Proc Natl Acad Sci U S A. 2007 ; 104: 20517-22.
29. van Grevenynghe J, Cubas RA, DaFonseca S, Metcalf T, Tremblay CL, Trautmann L, Sekaly RP, Schatzle J, Haddad EK. Foxo3a: an integrator of immune dysfunction during HIV infection. Cytokine Growth Factor Rev. 2012; 23: 215-21.

30. Chiacchiera F, Simone C. The AMPK-FoxO3A axis as a target for cancer treatment. Cell Cycle. 2010; 9: 1091-6.

31. Gomes AR, Zhao F, Lam EW. Role and regulation of the forkhead transcription factors FOXO3a and FOXM1 in carcinogenesis and drug resistance. Chin J Cancer. 2013; 32: $365-70$.

32. Lee JC, Espéli M, Anderson CA, Linterman MA, Pocock JM, Williams NJ, Roberts R, Viatte S, Fu B, Peshu N, Hien TT, Phu NH, Wesley E, et al. Human SNP links differential outcomes in inflammatory and infectious disease to a FOXO3-regulated pathway. Cell. 2013; 155: 57-69.

33. Im J, Hergert P, Nho RS. Reduced FoxO3a expression causes low autophagy in idiopathic pulmonary fibrosis fibroblasts on collagen matrices. Am J Physiol Lung Cell Mol Physiol. 2015; 309: L552-61.

34. Blankenbach KV, Schwalm S, Pfeilschifter J, Meyer ZHD. Sphingosine-1-phosphate receptor-2 antagonists: therapeutic potential and potential risks. Front Pharmacol. 2016; 7: 167.

35. Hou J, Chen Q, Zhang K, Cheng B, Xie G, Wu X, Luo C, Chen L, Liu H, Zhao B, Dai K, Fang X. Sphingosine 1-phosphate receptor 2 signaling suppresses macrophage phagocytosis and impairs host defense against sepsis. Anesthesiology. 2015; 123: 409-22.

36. Campos LS, Rodriguez YI, Leopoldino AM, Hait NC, Lopez BP, Castro MG, Sanchez ES, Maceyka M, Spiegel $\mathrm{S}$, Alvarez SE. Filamin A expression negatively regulates sphingosine-1-phosphate-induced NF- $\mathrm{BB}$ activation in melanoma cells by inhibition of Akt signaling. Mol Cell Biol. 2015; 36: 320-9.

37. Liu R, Li X, Qiang X, Luo L, Hylemon PB, Jiang Z, Zhang L, Zhou H. Taurocholate induces cyclooxygenase-2 expression via the sphingosine 1-phosphate receptor 2 in a human cholangiocarcinoma cell line. J Biol Chem. 2015; 290: 30988-1002.

38. Cui H, Okamoto Y, Yoshioka K, Du W, Takuwa N, Zhang W, Asano M, Shibamoto T, Takuwa Y. Sphingosine-1phosphate receptor 2 protects against anaphylactic shock through suppression of endothelial nitric oxide synthase in mice. J Allergy Clin Immunol. 2013; 132: 1205-14.e9.

39. Yang L, Han Z, Tian L, Mai P, Zhang Y, Wang L, Li L. Sphingosine 1-phosphate receptor 2 and 3 mediate bone marrow-derived monocyte/macrophage motility in cholestatic liver injury in mice. Sci Rep. 2015; 5: 13423.

40. Gomi H, Solomkin JS, Takada T, Strasberg SM, Pitt HA, Yoshida M, Kusachi S, Mayumi T, Miura F, Kiriyama S, Yokoe M, Kimura Y, Higuchi R, et al. TG13 antimicrobial therapy for acute cholangitis and cholecystitis. J Hepatobiliary Pancreat Sci. 2013; 20: 60-70. 
41. Lu J, Xie L, Liu C, Zhang Q, Sun S. PTEN/PI3k/AKT regulates macrophage polarization in emphysematous mice. Scand J Immunol. 2017; 85: 395-405.

42. Gong YQ, Huang W, Li KR, Liu YY, Cao GF, Cao C, Jiang Q. SC79 protects retinal pigment epithelium cells from UV radiation via activating Akt-Nrf2 signaling. Oncotarget. 2016; 7: 60123-32. https://doi.org/10.18632/ oncotarget.11164.

43. Yu JH, Tang HJ, Zhang WG, Zhu ZY, Ruan XX, Lu BC. Catheterization of the gallbladder: a novel mouse model of severe acute cholangitis. World J Gastroenterol. 2017; 23: 1771-9.
44. Cheng Y, Tian Y, Xia J, Wu X, Yang Y, Li X, Huang C, Meng X, Ma T, Li J. The role of PTEN in regulation of hepatic macrophages activation and function in progression and reversal of liver fibrosis. Toxicol Appl Pharmacol. 2017; 317: 51-62.

45. Ray A, Dittel BN. Isolation of mouse peritoneal cavity cells. J Vis Exp. 2010.

46. Jones AE, Puskarich MA. The surviving sepsis campaign guidelines 2012: update for emergency physicians. Ann Emerg Med. 2014; 63: 35-47. 